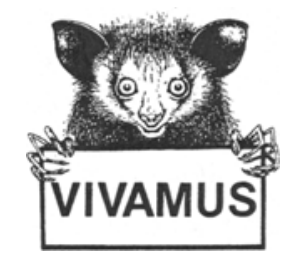

\title{
The Stone Tools of Capuchins (Cebus apella)
}

\author{
Gregory Charles Westergaard ${ }^{1,2}$ and Stephen J. Suomi ${ }^{1}$
}

Received April 3, 1995; accepted June 30, 1995

We examined the production of stone tools by capuchins (Cebus apella). Eleven subjects used five reduction techniques to produce 346 stone tools (48 cores and 298 flakes). They produced a sharp edge on $83 \%$ of the cores and largest flakes. Three monkeys later used a sample of these objects as cutting tools. These results demonstrate that monkeys produce lithic tools analogous to those produced by Oldowan hominids.

KEY WORDS: tools; artifacts; capuchins; Cebus apella; Oldowan; archaeology.

\section{INTRODUCTION}

A tool is an object which has been modified. The modification may or may not have been intentional, and the object itself may or may not have been used for a specific purpose (Schick and Toth, 1993). The archaeological record indicates that hominids first produced stone artifacts approximately 2.5 million years ago, during the Oldowan technological stage. Oldowan artifacts include cores, flakes, and battered stones (Leakey, 1971). Absent are the large bifacial forms that characterize the Acheulean technological stage, which emerged approximately 1.5-1.7 million years ago (Isaac, 1982).

The most widely used system for classifying Oldowan tool assemblages was developed by Leakey (1971). This system is based on the morphological characteristics and presumed functions of cores and flakes. Toth (1985) conducted replication experiments to determine the level of expertise that

\footnotetext{
${ }^{1}$ Laboratory of Comparative Ethology, National Institute of Child Health and Human Development, Bethesda, Maryland.

${ }^{2}$ To whom correspondence should be addressed at National Institutes of Health Animal Center, P.O. Box 529, Poolesville, Maryland 20837.
} 
is required for modern humans to produce Oldowan forms. He found that novice stoneworkers could produce most of the forms in Leakey's system and concluded that Lower Pleistocene hominids (Homo habilis and perhaps Australopithecus robustus) may have created similar forms simply as a consequence of flake production. Toth concluded that Oldowan artifacts represent technological "paths of least resistance" rather than preconceived "stylistic norms."

Wynn and McGrew (1989) compared the material culture of Oldowan hominids with that of wild chimpanzees. The most striking difference was that Oldowan hominids used flaked stone tools, whereas most tools used by wild chimpanzees are produced from vegetation (Boesch and Boesch, 1990). The authors noted many similarities between the two material cultures, including modes of artifact production, application of relatively simple spatial concepts, and gradation of manufactured tools. They concluded that all behavior patterns which can be inferred from the artifacts of early hominids fall within the range of the ape adaptive grade. In other words, Oldowan artifacts do not have characteristics that require humanlike language abilities, shared knowledge of arbitrary design, or other sophisticated cognitive processes (Davidson, 1991).

Capuchins (Cebus apella) use tools in numerous contexts. Instances of tool use that have been observed among wild capuchins include clubbing a snake with a stick and cracking open an oyster with a shell (Boinski, 1988; Fernandes, 1991). In captivity capuchins use stones as pounding and cutting tools and as throwing implements (Westergaard and Suomi, 1994ac). They employ several stone-reduction techniques and sometimes modify stones immediately before using them as tools (Westergaard and Suomi, 1994b).

We examined the production of stone tools by capuchins. Specifically, we sought to determine the characteristics of stone tools that they produce. Based on the extensive manipulative and tool-using propensities that have been demonstrated in capuchins (Beck, 1980; Chevalier-Skolnikoff, 1990; Visalberghi, 1990; Westergaard, 1994), we predicted that the monkeys would produce objects analogous to those that have been attributed to Oldowan hominids.

\section{METHOD}

Subjects. The subjects were 17 capuchins (Cebus apella) in four wellestablished groups. Included were 12 adults ( 7 males and 5 females), 4 juveniles ( 3 males and 1 female), and an infant. Adults ranged in age from 5.5 to 30 years, and juveniles from 1.5 to 3 years. The infant was 4 months 
old. The subjects were experienced in experiments on the use and modification of stone tools (Westergaard, 1994). They were housed in indoor cages $(2 \times 1 \times 2 \mathrm{~m})$, which are constructed of metal beams and bars with hard plastic perches. The cage flooring consists of metal beams and solid mesh. We occasionally placed wooden dowels $(2.5 \times 10 \mathrm{~cm})$ inside the cages. Food and water were available ad libitum.

Materials. We collected quartz and quartzite stones (Pellant, 1992) near the National Institutes of Health Animal Center in Poolesville, Maryland (U.S.A.). They weighed from 24 to $228 \mathrm{~g}$ (mean weight $=69 \mathrm{~g}$ ). We chose to limit stone weight in order to avoid injury to animals on the cage floor when other animals dropped or threw stones from perches.

Procedure. At the onset of each test session we placed between one and four stones on the floor inside a group's cage. We collected the stone material at the end of each session. We provided individual stones to the animals for $\leq 33.5 \mathrm{hr}$ in nine sessions (mean duration per stone $=8.0 \mathrm{hr}$ and 2.4 sessions). We provided 48 stones over a 4 -week period. An observer recorded the identities of subjects that used the reduction techniques defined in Table I. No human provided guidance to the subjects at any time.

One week after the stone-reduction sessions were completed, we presented 10 monkeys in two groups with a sample of stone artifacts and a container that held peanut butter that could be obtained only if the animals used a stone tool to cut through a plastic barrier (Westergaard and Suomi, $1994 \mathrm{a}, \mathrm{b})$. We conducted 20 trials over a 2 -hr period to demonstrate that the capuchins could use their flakes and cores as cutting tools.

Analysis. We defined flakes as pieces removed from a stone core. We defined flaked cores as stones from which at least one flake $>1 \mathrm{~cm}$ in width had been removed. Battered cores are stones with incidental damage. We considered the heaviest piece from each stone to be the stone's core. We determined the percentage difference in weight between cores and the

Table I. Operational Definitions of Stone-Reduction Techniques

\begin{tabular}{ll}
\hline \multicolumn{1}{c}{ Technique } & \multicolumn{1}{c}{ Operational definition } \\
\hline Anvil & Striking a stone against a cage structure \\
Bipolar & $\begin{array}{l}\text { Striking a stone against another stone positioned on a flat } \\
\text { surface }\end{array}$ \\
Throw & Throwing a stone against the floor \\
Hard-hammer percussion & Striking together stones held in each hand \\
Soft-hammer percussion & $\begin{array}{c}\text { Striking a stone with a piece of wood (either held in each } \\
\text { hand or positioned on a flat surface) }\end{array}$ \\
\hline
\end{tabular}


stones from which they were produced, the number of flakes that originated from each stone, and the maximum dimension of each flake. We then tested the sharpness of the most acute flaked edge on each core and large flake (flakes with a maximum dimension $>4 \mathrm{~cm}$ ). A flaked edge was sharp if we could use it to cut cleanly through a sheet of plastic $(0.1 \mathrm{~mm}$ thick).

\section{RESULTS}

The capuchins exhibited five stone-reduction techniques (Table II). They produced larger flakes when they used the anvil, bipolar, and throw techniques than when they used the hard-hammer and soft-hammer percussion techniques. Eleven subjects (seven adults and four juveniles) flaked stone. The infant struck stones against hard cage surfaces (perches, bars, and support structures). However, the infant's striking actions were not forceful enough to produce flakes.

The capuchins modified each stone that we presented to them (Fig. 1). They flaked 41 stones ( $85 \%)$ and battered 7 others (15\%). On average, the monkeys reduced flaked stones $33 \%$ (range $=2$ to $75 \%$ ), and battered stones $3 \%$ (range $=0$ to $13 \%$ ), in weight. An independent group's $t$ test indicates that the difference in weight reduction between flaked and battered stones is statistically significant $[t(46)=4.08, p \leq 0.0002]$. The subjects produced a sharp edge on $93 \%$ of the flaked cores and $29 \%$ of the battered cores.

Table II. Stone-Reduction Techniques of Capuchins

\begin{tabular}{|c|c|c|c|c|c|c|c|}
\hline \multirow[b]{2}{*}{ Subject } & \multirow[b]{2}{*}{$\begin{array}{c}\text { Age } \\
\text { class }^{a}\end{array}$} & \multirow[b]{2}{*}{$\operatorname{Sex}^{b}$} & \multirow[b]{2}{*}{ Anvil } & \multirow[b]{2}{*}{ Bipolar } & \multirow[b]{2}{*}{ Throw } & \multicolumn{2}{|c|}{ Percussion } \\
\hline & & & & & & $\begin{array}{c}\text { Hard } \\
\text { hammer }\end{array}$ & $\begin{array}{c}\text { Soft } \\
\text { hammer }\end{array}$ \\
\hline Virgil & A & M & $x$ & $\mathbf{x}$ & $\mathbf{x}$ & $\mathbf{x}$ & $\mathrm{x}$ \\
\hline Morris & A & $\mathbf{M}$ & $\mathbf{x}$ & $\mathrm{x}$ & $x$ & $\mathbf{x}$ & $\mathbf{x}$ \\
\hline Pierce & A & M & $\mathrm{x}$ & & & & \\
\hline Simon & A & $\mathbf{M}$ & $\mathbf{x}$ & $x$ & $\mathbf{x}$ & & \\
\hline Aslan & $\mathbf{A}$ & $\mathbf{M}$ & $\mathbf{x}$ & & & & \\
\hline Tigger & A & $\mathbf{F}$ & $\mathbf{x}$ & & & & \\
\hline Carlina & A & F & $\mathbf{x}$ & & & & \\
\hline Willie & $\mathbf{J}$ & $\mathbf{M}$ & $\mathbf{x}$ & $\mathbf{x}$ & $\mathrm{x}$ & $\mathrm{x}$ & $\mathrm{x}$ \\
\hline Corey & J & $\mathbf{M}$ & $\mathbf{x}$ & $\mathbf{x}$ & & $\mathbf{x}$ & $\mathrm{x}$ \\
\hline Mowgli & J & $\mathbf{M}$ & $\mathbf{x}$ & $\mathbf{x}$ & $\mathbf{x}$ & & $\mathrm{x}$ \\
\hline Verner & $\mathbf{J}$ & F & $\mathbf{x}$ & $\mathrm{x}$ & $\mathrm{x}$ & $\mathrm{x}$ & \\
\hline
\end{tabular}

${ }^{a} \mathrm{~A}$, adult; J, juvenile.

${ }^{b} \mathrm{M}$, male; $\mathrm{F}$, female. 

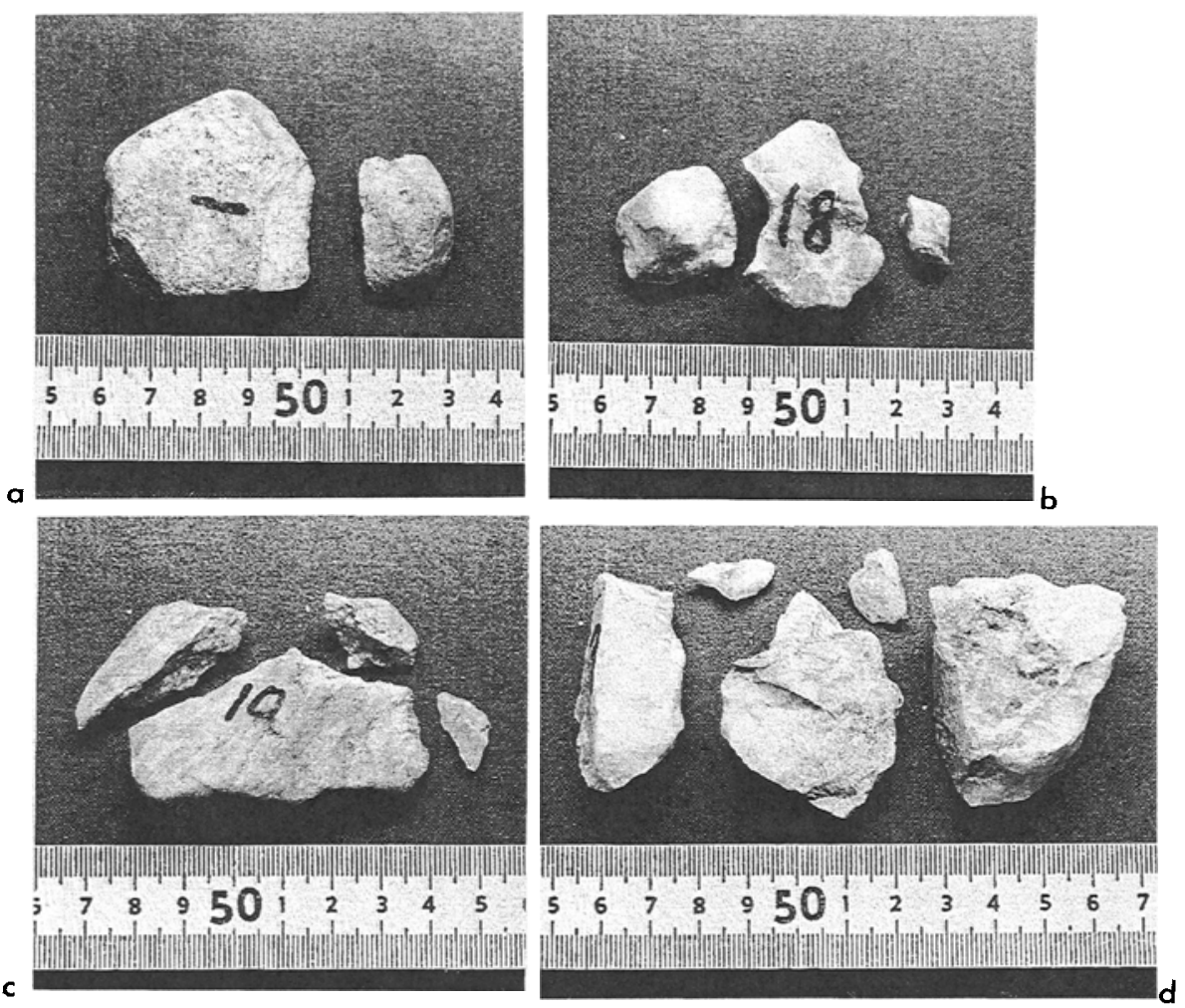

Fig. 1. A sample of stone tools produced by capuchins: (a) a core from which a single flake has been removed; (b) a core that has been flaked along two opposite edges; (c) a core that has been flaked along three adjoining edges; and (d) a core (right) and four flakes. The scale is in centimeters.

We recovered 298 flakes (mean number of recovered flakes per stone $=6.2$; range $=0$ to 20 ). The maximum dimension of individual flakes ranged from 0.1 to $5.3 \mathrm{~cm}$ (Table III). The capuchins produced a sharp edge on all flakes $>4 \mathrm{~cm}$ in length.

Three capuchins (Jeb, Morris, and Virgil) used stone tools-flakes and flaked cores-for cutting in each of the 20 trials. They inserted artifacts into the apparatus and then pushed down in a back-and-forth motion (Westergaard and Suomi, 1994b). The sharp edges of flaked artifacts were most effective for cutting acetate. The animals did not show an obvious preference for selecting stone flakes versus flaked stone cores; however, larger artifacts (>4 cm in length) appeared to be most effective for use as tools in this experiment. 
Table III. Relative Distribution of Flake Sizes

\begin{tabular}{lcc}
\hline Maximum dimension & $N$ & Relative percentage \\
\hline$>4$ and $\leq 6 \mathrm{~cm}$ & 10 & 3 \\
$>2$ and $\leq 4 \mathrm{~cm}$ & 59 & 20 \\
$>1$ and $\leq 2 \mathrm{~cm}$ & 85 & 29 \\
$\leq 1 \mathrm{~cm}$ & 144 & 48 \\
Total & 298 & - \\
\hline
\end{tabular}

\section{DISCUSSION}

Calvin (1992) suggested that throwing facilitated the use of tools by hominids because stone missiles would sometimes have fractured in close proximity to fallen prey. The sharp edges of these artifacts would then have been readily accessible for carcass processing activities. Our capuchins produced stone artifacts by throwing, as well as by techniques which involved direct percussion. These techniques are believed to have been used by the earliest toolmaking hominids (Schick and Toth, 1993). It should be noted that throwing is the favored stone-flaking technique of a captive bonobo (Toth et al., 1993). Further research will be useful for determining the extent to which throwing and other stone-flaking techniques are behavioral characteristics shared among phylogenetically diverse primate species.

In many ways the capuchins' stone tool production skills were unsophisticated relative to those of Homo habilis as manifested in the archaeological record. The monkeys did not consistently search for acute core angles, use flake scars as striking platforms, or produce large flakes through direct hand-held percussion. Many of the capuchins' stone cores retain a high proportion of their original cortex and show marginal (noninvasive) flake scars. Most of their flakes are $\leq 2 \mathrm{~cm}$ long, and only a few show evidence of retouching (modification after detachment). Toth $e t$ al. (1993) have noted similar limitations in the stone-flaking activities of a bonobo, and Wright (1972) described limited stone-flaking by an orangutan. These findings indicate that nonhuman primate stone-flaking skills are simpler than those of Homo habilis and other toolmaking hominids. We hypothesize that the earliest hominid or protohominid toolmakers were similarly constrained and that their artifacts would probably resemble stone tools produced by great apes and capuchins. Later refinement of relatively 
simple stone-reduction techniques would have facilitated production of larger, more complex bifacial forms.

Paleoanthropologists have largely ignored the activities of nonhuman primates in reconstructing archaeological sites (McGrew, 1993). This is surprising because fossilized primates have been found at several locations where stone tools are believed to have been used in prehistoric times (Potts, 1988). Wild capuchins consume a broad variety of foods and extract prey while foraging (Fragaszy, 1986; Izawa, 1979; Janson, 1985). Several authors have hypothesized that the destructive foraging habits of capuchins underlie their tool-using and toolmaking abilities (Parker and Gibson, 1977; Westergaard and Fragaszy, 1987). Wild capuchins use tools at least occasionally (Boinski, 1988; Chevalier-Skolnikoff, 1990; Fernandes, 1991), and we speculate that capuchins may produce and use stone tools within their New World habitat.

We plan to conduct additional research on the lithic capacities of capuchins. One project will illuminate more fully the range of contexts in which capuchins produce and use stone artifacts. A second project will examine the capuchins' abilities to transport and to cache stone material, a third will examine the archaeological sites that they produce when they use and manufacture stone tools (McGrew, 1992), and a fourth will examine the range of materials that capuchins will use as tools. We believe that the tool-using and toolmaking skills of capuchins provide an interesting model of analogous capabilities in prehistoric hominids and extant great apes.

\section{ACKNOWLEDGMENTS}

Dr. Westergaard was supported by an Intramural Research Training Award from the National Institute of Child Health and Human Development. The subjects were housed in Laboratory of Comparative Ethology facilities at the National Institutes of Health Animal Center in Poolesville, MD. We thank Clara Menuhin-Hauser and Lily V. H. M. H. Westergaard for commenting on an early draft of the manuscript.

\section{REFERENCES}

Beck, B. B. (1980). Animal Tool Behavior: The Use and Manufacture of Tools by Animals, Garland STPM Press, New York.

Boesch, C., and Boesch, H. (1990). Tool use and tool making in wild chimpanzees. Folia Primatol 54: 86-99.

Boinski, S. (1988). Use of a club by a white-faced capuchin (Cebus capucinus) to attack a venomous snake (Bothrops asper). Am. J. Primatol. 14: 177-179.

Calvin, W. (1993). The unitary hypothesis: A common neural circuitry for novel manipulations, language, plan-ahead, and throwing? In Gibson, K. R., and Ingold, T. (eds.), Tools, 
Language, and Cognition in Human Evolution, Cambridge University Press, Cambridge, pp. 230-250.

Chevalier-Skolnikoff, S. (1990). Tool use by wild Cebus monkeys at Santa Rosa National Park, Costa Rica. Primates 31: 375-383.

Davidson, I. (1991). The archaeology of language origins-A review. Antiquity 65: 39-48.

Fernandes, M. E. B. (1991). Tool use and predation of oysters (Crassostrea rhizophorae) by the tufted capuchin, Cebus apella apella, in brackish water mangrove swamp. Primates 32: 529-531.

Fragaszy, D. M. (1986). Time budgets and foraging behavior in wedgecapped capuchins (Cebus olivaceous): Age and sex differences. In King, F., and Taub, D. (eds.), Current Perspectives in Primate Social Dynamics, Van Nostrand, New York, pp. 159-174.

Isaac, G. L. (1982). The earliest archaeological traces. In Clark, J. D (ed.), The Cambridge History of Africa, Vol. 1. From the Earliest Times to c. 500 B.C., Cambridge University Press, Cambridge.

Izawa, K. (1979). Foods and feeding behavior of wild black-capped capuchins (Cebus apella). Primates 20: 57-76.

Janson, C. H. (1985). Aggressive competition and individual food consumption in wild brown capuchin monkeys (Cebus apella). Behav. Ecol. Sociobiol. 18: 125-138.

Leakey, M. D. (1971). Olduvai Gorge, Vol. 3. Excavations in Beds I and II, Cambridge University Press, London.

McGrew, W. C. (1992). Chimpanzee Material Culture. Cambridge University Press, Cambridge.

McGrew, W. C. (1993). The intelligent use of tools: Twenty propositions. In Gibson, K. R., and Ingold, T. (eds.), Tools, Language, and Cognition in Human Evolution, Cambridge University Press, Cambridge, pp. 151-170.

Parker, S. T., and Gibson, K R. (1977). Object manipulation, tool use and sensorimotor intelligence as feeding adaptations in Cebus monkeys and great apes. J. Hum. Evol. 6: 623-641.

Pellant, C. (1992). Rocks and Minerals, Dorling Kindersley, New York.

Potts, R. (1988). Early Hominid Activities at Olduvai, Aldine de Gruyter, New York.

Schick, K. D., and Toth, N. (1993). Making Silent Stones Speak: Human Evolution and the Dawn of Technology, Simon \& Schuster, New York.

Toth, N. (1985). The Oldowan reassessed: A close look at early stone artifacts. J. Archaeol. Sci. 12: 101-120.

Toth, N., Schick, K. D., Savage-Rumbaugh, E. S., Sevcik, R. A., and Rumbaugh, D. M. (1993). Pan the tool-maker: Investigations into the stone tool-making and tool-using capabilities of a bonobo (Pan paniscus). J. Anchaeol. Sci. 20: 81-91.

Visalberghi, E. (1990). Tool use in Cebus. Folia Primatol. 54: 146-154.

Westergaard, G. C. (1994). The subsistence technology of capuchins. Int. J. Primatol. 15: 899-906.

Westergaard, G. C., and Fragaszy, D. M. (1987). The manufacture and use of tools by capuchin monkeys (Cebus apella). J. Comp. Psychol. 101: 159-168.

Westergaard, G. C., and Suomi, S. J. (1994a). The use and modification of bone tools by capuchin monkeys. Curr. Anthropol. 35: 75-77.

Westergaard, G. C., and Suomi, S. J. (1994b). A simple stone-tool technology in monkeys. J. Hum. Evol. 27: 399-404.

Westergaard, G. C., and Suomi, S. J. (1994c). Aimed throwing of stones by tufted capuchin monkeys (Cebus apella). Hum. Evol. 9: 323-329.

Wright, R. V. (1972). Imitative learning of a flaked tool technology: The case of an orangutan. Mankind 8: 296-306.

Wynn, T., and McGrew, W. C. (1989). An ape's view of the Oldowan. Man 24: 383-398. 